\title{
De algemene competenties van de medisch specialist in de toekomst
}

\author{
O.P. Bleker, Th.J. ten Cate, R.S.G. Holdrinet
}

\section{Samenvatting}

Sinds medio 2002 werkt het Centraal College Medische Specialismen (CCMS) van de KNMG aan de modernisering van de medisch-specialistische opleidingen. Een eerste mijlpaal in dit proces is het vastleggen van algemene competenties die voor iedere specialist gelden en die de inhoudelijke basis moeten worden voor de moderne specialistenopleiding. Het document waarin deze competenties in 2003 zijn vastgelegd is in dit artikel integraal opgenomen. De competenties zijn ontleend aan het model van de 'Canadian Medical Education Directives for Specialists 2000' (CanMEDS 2000), aangepast aan de Nederlandse situatie, onder meer op basis van een rapport van een werkgroep die is uitgegaan van het 'Raamplan Artsopleiding 2001'. In 2006 zullen alle medisch-specialistische opleidingen een programma moeten hebben dat gebaseerd is op deze algemene competenties, waar mogelijk specifiek ingevuld, en zal de beoordeling van assistenten in opleiding gericht moeten zijn op deze competenties. (Bleker OP, Cate ThJ ten, Holdrinet RSG. De algemene competenties van de medisch specialist in de toekomst. Tijdschrift voor Medisch Onderwijs 2004;23(1): 4-14.)

\section{Inleiding}

Na ruim een jaar voorbereiding is in september 2003 in het Centraal College Medische Specialismen (CCMS) een nieuw model van eindtermen, geformuleerd als competenties, vastgesteld en voorgeschreven dat vanaf 1 januari 2006 voor alle opleidingen geldig zal zijn. Hieronder volgt integraal de tekst waarin deze algemene competenties zijn vastgelegd, ${ }^{1}$ aangevuld met een discussie over de bruikbaarheid ervan.

\section{Tekst van het Centraal College Medische Specialismen}

De hervorming van de Nederlandse specialistische opleiding die het College voor ogen heeft is gericht op het bereiken van zorgvuldig geformuleerde eindtermen voor iedere opleiding. Deze eindtermen zijn gedeeltelijk specialisme-gebonden, maar in belangrijke mate ook algemeen geldig. Het CCMS heeft daarom besloten generale competenties voor alle opleidingen op te stellen, geformuleerd als algemene competenties die de bekwaamheid van de Nederlandse specialist beschrijven. Het is denkbaar dat ook andere medische vervolgopleidingen van het hier beschreven model gebruik zouden willen maken. Dat lijkt, met beperkte aanpassingen, zeer wel mogelijk.

Met de term competentie wordt gedoeld op een gedragsrepertoire waaruit blijkt dat men toegerust is voor de praktijk of een onderdeel daarvan. Competenties zijn contextgebonden en ondeelbaar, d.w.z. clusters van vaardigheden, kennis, attituden, eigenschappen en inzichten. Ze zijn verbonden met activiteiten of taken. Ze zijn veranderlijk in de tijd en dus wel leerbaar. ${ }^{2}$ De juridische bedoeling van de term ('bevoegdheid') is hier niet aan de orde. 


\section{Totstandkoming van de Algemene competenties}

Algemene competenties zijn competenties die voor ieder specialisme van toepassing zijn. Bij de totstandkoming van de Algemene competenties is gebruik gemaakt van een advies van een in augustus 2002 ingestelde Werkgroep Algemene Eindtermen die op basis van het Raamplan $2001^{3}$ een voorstel ${ }^{4}$ heeft voorbereid én het uit 1996 stammende rapport 'Skills for the New Millennium' van het CanMEDS 2000-project, 5 waarin een vergelijkbare exercitie in Canada is ingezet als die welke het College voor ogen staat. De Algemene competenties zijn op basis van deze drie documenten geformuleerd door een hiertoe in februari 2003 ingestelde Adviescommissie CCMS. Vervolgens zijn ook het College voor de Sociale Geneeskunde en het College voor de Huisarts- en Verpleeghuisgeneeskunde uitgenodigd zich aan te sluiten bij de algemene competenties.

De Algemene competenties zijn ingedeeld in een zevental competentiegebieden. Deze indeling wordt gevoerd om te komen tot een overzicht van werkbare, begrijpelijke, toetsbare en goed te onthouden competenties.

\section{Terminologie en niveau van eindtermen}

Eindtermen beschrijven een wenselijke en duurzame competentie die resultaat is van veelsoortige intentionele leerprocessen. De Algemene competenties beschrijven de eindtermen van de opleidingen als geheel. Eindtermen kunnen op verschillende niveaus gepositioneerd worden. De zogeheten Piramide van Miller ${ }^{6}$ geeft deze niveau-indeling goed weer door te beschrijven waartoe de persoon (specialist of agio) in staat moet zijn.

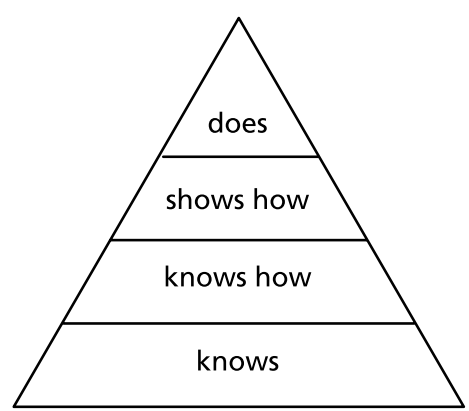

Figuur 1. De Piramide van Miller.

De beschreven algemene competenties zijn gericht op het hoogste niveau van de piramide ('does') en impliceren dus 'performance' - good practice, bekwaam handelen - in de praktijk. Hiermee zijn de eindtermen geformuleerd als het gedrag dat van de specialist mag worden verwacht. Dit is een stap verder dan het kunnen tonen van kennis en vaardigheden; het gaat om het daadwerkelijk handelen. Het woord 'kunnen' is daarom bij de formulering van de Algemene competenties niet gehanteerd.

\section{Relatie met het Raamplan 2001}

In het 'Raamplan Artsopleiding 2001' worden de algemene eindtermen beschreven, gericht op het functioneren als arts. Daarbij worden vier rubrieken onderscheiden waarbinnen een groot aantal specifieke termen gedetailleerd zijn geformuleerd:

1. Medische aspecten.

2. Wetenschappelijke aspecten.

3. Persoonlijke aspecten.

4. Aspecten in relatie tot de maatschappij en het gezondheidszorgsysteem.

Deze eindtermen die binnen deze rubrieken genoemd worden zijn opnieuw geordend en betrokken bij de opstelling van de Algemene competenties. Het college heeft 
aansluiting gevonden bij de eindtermen van het Raamplan 2001, maar heeft ervoor gekozen om af te wijken van de Raamplan-indeling, mede met het oog op de praktische uitvoerbaarheid van een herziening van de specialistische opleidingen, en de toetsbaarheid van de Algemene competenties. Er is daarom gekozen voor scherpe definities van algemene competenties, waar mogelijk gebruikmakend van formuleringen die ook elders vruchtbaar zijn gebleken.

\section{Competentiegebieden}

Gekozen is voor een zevental competentiegebieden:

1. Medisch handelen.

2. Communicatie.

3. Samenwerking.

4. Kennis en wetenschap.

5. Maatschappelijk handelen.

6. Organisatie.

7. Professionaliteit.

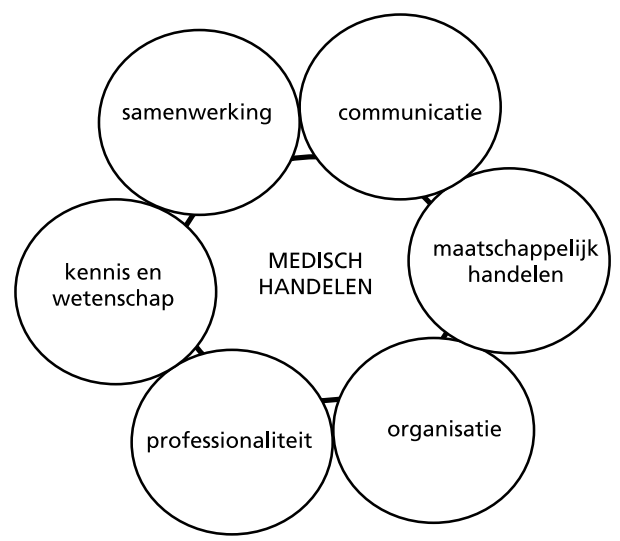

Figuur 2. Competentiegebieden van de specialist van de toekomst.

Deze competentiegebieden komen in belangrijke mate overeen met de CanMEDS 2000-roles, waarin de functie van de specialist telkens is weergegeven als rol:
(1) Medical Expert / Clinical Decision Maker, (2) Communicator, (3) Collaborator, (4) Scholar, (5) Health Advocate, (6) Manager en (7) Professional. Om linguïstische redenen is ervoor gekozen in de Nederlandse taal geen rol-aanduidingen te hanteren.

\section{Toelichting bij de competentie- gebieden en de Algemene competenties}

De competentiegebieden zijn toegelicht met een algemene omschrijving. De Algemene competenties zijn geformuleerd in termen van operationeel gedrag. Het gaat hier dus niet meer om een vaardigheid die getoond moet kunnen worden in een beoordelingssituatie, c.q. een mogelijk gedragsrepertoire, maar om het feitelijke gedrag in de praktijk. Een competente specialist is dus niet alleen in staat om, bijvoorbeeld, goed te luisteren (Algemene competentie 2:2), maar doet dit ook in de dagelijkse praktijk. Er is derhalve sprake van competenties die naast een gedragsvermogen een gedragsbereidheid impliceren. Hiermee wordt voldaan aan het streven om competenties te beschrijven op het hoogste niveau van Miller (niveau 'does'). Bij de beoordeling van agio's zal daarom in late opleidingsfasen overwegend sprake moeten zijn van observatie van het competent dagelijks handelen.

\section{Medisch handelen}

Het medisch handelen vorm het centrale competentiegebied dat gebruik maakt van alle overige competenties. Medisch handelen in enge zin is gericht op vakdeskundige expertise.

\section{Omschrijving van het competentiegebied} De specialist overziet het voor het eigen denken en handelen relevante kennisdomein en kan snel en doelmatig medisch- 
wetenschappelijke informatie vinden. Hij of zij voert op een gesystematiseerde wijze een (hetero)anamnese en lichamelijk onderzoek uit en komt op basis hiervan tot rationele hypothesen over mogelijke oorzaken en gevolgen van gedane bevindingen. Hij of zij beheerst de voor algemeen medisch onderzoek en behandeling noodzakelijke handvaardigheden alsmede de vaardigheden noodzakelijk voor acute hulp ter ondersteuning van vitale lichaamsfuncties. Hij of zij stelt in relatie met geformuleerde hypothesen een verantwoord beleid vast ten aanzien van aanvullende diagnostiek, behandeling, patiëntenzorg en preventie. Dit, met respect voor de wensen van de patiënt, zijn of haar familie, en met rekenschap van de gebruikelijke wijze van aanpak zoals die is gebaseerd op een rationele en wetenschappelijk gefundeerde geneeskunde. De specialist maakt waar nodig een passend gebruik van medische technologie en is zich daarbij bewust van de voor- en nadelen die zijn verbonden aan specifieke interventies.

\section{Algemene competenties Medisch handelen}

1:1. De specialist bezit adequate kennis en vaardigheid naar de stand van het vakgebied

Dit vormt de basis voor elk medisch handelen. Er hoeft geen sprake te zijn van encyclopedische parate kennis, maar voldoende kennis, inzicht en vaardigheid om doelmatige, hoogwaardige patiëntenzorg te verlenen.

1:2. De specialist past het diagnostisch, therapeutisch en preventief arsenaal van het vakgebied goed en waar mogelijk evidence based toe

Hieronder valt het kunnen definiëren van de hulpvraag, het afnemen van een rele- vante, beknopte en accurate anamnese, het doelmatig uitvoeren van een doelmatig lichamelijk onderzoek, het uitvoeren van relevante procedures om gegevens te verzamelen, te analyseren en te interpreteren, het opstellen van een gerichte differentiaal diagnose, het stellen van diagnoses en het instellen van de juiste behandeling om het probleem van de patiënt te helpen oplossen.

\section{1:3. De specialist levert effectieve en} ethisch verantwoorde patiëntenzorg

Dit impliceert het nemen van de juiste beslissingen in een afweging tussen diagnostische en therapeutische mogelijkheden en hun inperking op grond van de belasting voor de patiënt en andere randvoorwaarden.

1:4. De specialist vindt snel de vereiste informatie en past deze goed toe

Hieronder valt het weten te stellen van de juiste, patiënt-gerelateerde vragen, het systematisch zoeken naar onderbouwing in de literatuur, het kritisch evalueren van medische literatuur en ander bewijs om de klinische besluitvorming te optimaliseren.

\section{Communicatie}

\section{Omschrijving van het competentiegebied}

De specialist verschaft in juiste, begrijpelijke en empathische bewoordingen aan een patiënt (of vertegenwoordiger) de noodzakelijke en gewenste (soms ook onaangename) informatie en betracht voor deze taak de noodzakelijke tijd en geduld. Hij of zij kan in beknopte termen mondeling en schriftelijk verslag doen van een ziektecasus met formulering van (voorlopige) conclusies en resterende vragen ten aanzien van diagnostiek, behandeling en zorgverlening. 


\section{Algemene competenties Communicatie}

\section{2:1. De specialist bouwt effectieve} behandelrelaties met patiënten op

Hieronder valt het vormen en onderhouden van een goede verstandhouding met (familie van) patiënten en het cultiveren van een omgeving die gekenmerkt wordt door begrip, vertrouwen, empathie en vertrouwelijkheid.

\section{2:2. De specialist luistert goed en verkrijgt} doelmatig relevante patiëntinformatie

Hieronder valt het tonen van interesse in de ideeën, zorgen en verwachtingen van de patiënt over het ontstaan, de aard en behandeling van zijn of haar ziekte of probleem. Specialisten zijn in staat om de invloed van factoren als leeftijd, geslacht, etnisch-culturele achtergrond, sociaal netwerk en emotie naar waarde in te schatten.

\section{2:3. De specialist bespreekt medische} informatie goed met patiënten en familie

Dit impliceert het vermogen om een patiënt op invoelende wijze en met respect te informeren en te adviseren, en intussen begrip, discussie en de actieve deelname van de patiënt in beslissingen over zijn of haar behandeling te bevorderen. Daaronder valt het kunnen luisteren naar een patiënt om een optimale en consistente patiëntenzorg voor de patiënt en zijn of haar familie te waarborgen. Verder betreft dit het verifiëren van het begrip van de patiënt. Eveneens vraagt dit om het vermogen om duidelijke en accurate dossiers bij te houden. Dit alles geschiedt in overeenstemming met de wettelijke regels die hiervoor bestaan.

\section{2:4. De specialist doet adequaat mondeling} en schriftelijk verslag over patiëntencasus

De specialist verschaft tijdens overdrachten en patiëntenbesprekingen een beknopt maar accuraat overzicht over de problemen van de patiënt, en verklaart en verdedigt waar nodig het ingezette diagnostische en therapeutische beleid, en formuleert duidelijke vraagstellingen voor effectief intercollegiaal overleg.

\section{Samenwerking}

Omschrijving van het competentiegebied De specialist toont de eigen beperkingen in kennis, vaardigheden en ervaring te beseffen en demonstreert dit o.a. door de bereidheid tot overleg met collegae c.q. zorgt, in een blijvende sfeer van persoonlijke betrokkenheid en aanvaarde verantwoordelijkheid, voor juiste consultatie of verwijzing. Hij of zij heeft inzicht in de consequenties van het eigen handelen voor andere betrokken professionals rond de patiëntenzorg van de patiënt en functioneert goed in teamverband.

\section{Algemene competenties Samenwerking}

\section{3:1. De specialist overlegt doelmatig met collegae en andere zorgverleners}

Dit impliceert het vermogen om onderzoek, behandeling en follow-up beleid te ontwikkelen samen met de patiënt en andere zorgverleners. Onder deze aanpak valt het kennen van de rollen en deskundigheid van de andere betrokkenen, het informeren van, en betrekken van de patiënt en zijn of haar familie bij de besluitvorming en het expliciet integreren van de meningen van de patiënt en zorgverleners in de behandelplannen.

\section{3:2. De specialist verwijst adequaat}

Dit veronderstelt inzicht in de grenzen van de eigen deskundigheid en mogelijkheden en bekendheid met de mogelijkheden van andere medische zorgdisciplines en deskundigheden van anderen in de patiëntenzorg. 


\section{3:3. De specialist levert effectief} intercollegiaal consult

Hieronder valt het presenteren van goed onderbouwde evaluaties en aanbevelingen, zowel mondeling als schriftelijk, naar aanleiding van een intercollegiaal consult door een collega of een andere zorgverlener.

3:4. De specialist draagt bij aan effectieve interdisciplinaire samenwerking en ketenzorg

Hieronder valt inzicht in de zorgketen van individuele patiënten, het effectief communiceren met andere zorgverleners en het kennen van activiteiten in ziekenhuizen, praktijken en andere instellingen, zoals commissies, research, onderwijs en kennisverwerving. Het impliceert het onderkennen van de vakgebieden van teamleden, het respecteren van de meningen en rollen van individuele teamleden, het bijdragen aan een gezonde teamontwikkeling en conflictoplossing en het bijdragen aan de taak van het team middels de eigen deskundigheid. Onder deze Algemene competentie valt ook het zorgdragen voor een zorgvuldige overdracht van patiënteninformatie en het nemen van verantwoordelijkheid voor de continuïteit van de zorg voor de patiënt.

\section{Kennis en wetenschap}

\section{Omschrijving van het competentiegebied}

De specialist kan de vele wetenschappelijke aspecten zoals die zijn verweven met de klinische praktijk onderkennen, kritisch beschouwen en waar mogelijk op basis van eigen waarneming en ervaring komen tot vragen voor wetenschappelijk onderzoek en doet aan bij- en nascholing van zich zelf en anderen, conform hedendaagse opvattingen betreffende educatie, kwaliteitszorg en (continue) professionele ontwikkeling.

\section{Algemene competenties Kennis en wetenschap}

\section{4:1. De specialist beschouwt medische informatie kritisch}

Dit betreft het werken in de geest van wetenschappelijk onderzoek en het gebruiken van rationele onderbouwingen bij klinische besluitvorming. Net als bij Medisch handelen valt hieronder het kunnen stellen van de juiste vragen, het doelmatig zoeken naar, en het beoordelen van de kwaliteit van de onderbouwing in de literatuur en het op de hoogte blijven van de onderbouwde zorgnormen voor de aandoeningen die in zijn of haar praktijk het meest voorkomen.

\section{4:2. De specialist bevordert de verbreding} van en ontwikkelt de wetenschappelijke vakkennis

Hoewel niet elke specialist zelfstandig wetenschappelijk onderzoek zal verrichten, dient hij of zij wel de vaardigheden te hebben om deel te nemen aan gemeenschappelijke researchprojecten, kwaliteitsborging of de ontwikkeling van richtlijnen die relevant zijn voor de klinische praktijk.

4:3. De specialist ontwikkelt en onderhoudt een persoonlijk bij- en nascholingsplan

Dit impliceert het nemen van verantwoordelijkheid om de persoonlijke leerbehoefte vast te stellen. Daaronder valt het stellen van persoonlijke leerdoelen, het kiezen van de geschikte leermethoden en het evalueren van de eigen leerresultaten met het oog op een optimale praktijkvoering.

4:4. De specialist bevordert de deskundigheid van studenten, agio's, collegae, patiënten en andere betrokkenen bij de gezondheidszorg

Hieronder valt het doorgeven van het medisch vak aan volgende generaties via 
onderwijs en op andere wijze. Dit impliceert het helpen van anderen hun leerbehoeften en ontwikkelrichting vast te stellen, het geven van opbouwende feedback en het toepassen van de principes van kennisverwerving bij volwassenen in de interactie met studenten, agio's, maar ook met patiënten, collega's en andere betrokkenen bij de gezondheidszorg.

\section{Maatschappelijk handelen}

\section{Omschrijving van het competentiegebied}

Specialisten zijn onderdeel van de maatschappij en moeten zich bewust zijn van hun rol als behartigers van het belang van de volksgezondheid, als reactie op de uitdagingen die gesteld worden door de sociale, milieu- en biologische factoren die de gezondheid van patiënten en de samenleving beïnvloeden. De specialist beseft dat deze belangenbehartiging een essentieel onderdeel is van het bevorderen van de gezondheid op het niveau van de patiënt, de praktijk en de gemeenschap. Het bevorderen van de gezondheid is vervat in de individuele en collectieve reacties van specialisten bij het beïnvloeden van de volksgezondheid en het beleid.

\section{Algemene competenties Maatschappelijk handelen}

\section{5:1. De specialist kent en herkent de determinanten van ziekte}

Hieronder valt het kunnen herkennen, inschatten en reageren op de psychosociale, economische en biologische factoren die de gezondheid van patiënten beïnvloeden. De specialist verwerkt informatie over de bepalende gezondheidsfactoren in de patiëntenzorg van individuele patiënten en van de gemeenschap. Op arts-patiëntniveau betreft dit (1) het kunnen aanpassen van de behandeling van patiënten en informatieverstrekking aan patiënten teneinde hun gezondheid te bevorderen en het begrip voor het beleid te vergroten, (2) het leren omgaan met de ziekte te bevorderen en het stimuleren tot een actieve deelname in de medische besluitvorming. Hieronder valt op maatschappelijk niveau (1) het identificeren van risicogroepen en het herkennen van maatschappelijke ontwikkelingen die de volksgezondheid beïnvloeden, (2) het herkennen van relevant overheidsbeleid en (3) het in voorkomende gevallen bijdragen aan beleid dat de volksgezondheid gunstig beïnvloedt.

\section{5:2. De specialist bevordert de gezondheid} van patiënten en de gemeenschap als geheel

Hieronder valt het toepassen van medische deskundigheid in situaties die niet te maken hebben met directe patiëntenzorg, bijvoorbeeld bij het afleggen van verklaringen als medisch deskundige en het geven van presentaties.

\section{5:3. De specialist handelt volgens de} relevante wettelijke regelgeving

De specialist is op de hoogte van de relevante wettelijke regelgeving en werkt in overeenstemming met de eigen juridische positie en die van patiënten, waaronder die met betrekking tot het beroepsgeheim. Hij of zij onderkent daarbij de gevolgen voor het medisch handelen.

\section{5:4. De specialist treedt adequaat op bij incidenten in de zorg}

De specialist herkent incidenten in de patiëntenzorg en onderkent eigen fouten en die van anderen en heeft geleerd deze bespreekbaar en hanteerbaar te maken, met het oog op een adequaat beleid in de gegeven situatie, op de leerzaamheid van het voorval, op preventie in de toekomst en op het belang van de patiënt. De spe- 
cialist is bekend met de wijze waarop incidenten lege artis worden gemeld, en weet om te gaan met klachten over de patiëntenzorg.

\section{Organisatie}

\section{Omschrijving van het competentiegebied}

Specialisten functioneren als manager in hun dagelijkse beslissingen over taken, beleid, medewerkers en middelen. Ze doen dit in het kader van individuele patiëntenzorg, praktijkorganisaties, en in de bredere context van het gezondheidszorgsysteem. Derhalve stelt de specialist prioriteiten, voert taken doelmatig uit in teamverband met collega's, en neemt rationele beslissingen bij de inzet van beperkte middelen. Specialisten zijn beschikbaar voor de positie van leider binnen de context van de gezondheidszorgorganisatie. De specialist overziet in deze positie de vele bijkomende belangen en aspecten die in de patiëntenzorg spelen (zoals bijv. administratieve, financieel-economische en beheersmatige) en weet hiermee op ethisch, juridisch en economisch verantwoorde wijze om te gaan.

\section{Algemene competenties Organisatie}

6:1. De specialist organiseert het werk naar een balans in patiëntenzorg en persoonlijke ontwikkeling

Hieronder valt het effectief kunnen toepassen van time management en zelfevaluatie om realistische verwachtingen te formuleren en te komen tot een evenwichtige levensstijl.

\section{6:2. De specialist werkt effectief en} doelmatig binnen een gezondheidszorgorganisatie

Dit betreft het hebben van inzicht in de rollen en verantwoordelijkheden van de specialisten, de organisatie en functioneren van het gezondheidszorgsysteem en het maatschappelijk krachtenspel. Hieronder valt het doelmatig in teams met collega's kunnen werken, het leiden van een praktijk en het functioneren binnen bredere managementsystemen in organisaties, zoals ziekenhuiscommissies, of landelijke representatieve functies binnen de gezondheidszorg.

6:3. De specialist besteedt de beschikbare middelen voor de patiëntenzorg verantwoord

Hoewel de belangen van de patiënt altijd centraal staan, impliceert dit het vermogen om grondige afwegingen te maken t.a.v. de toewijzing van middelen op basis van het nut voor de individuele patiënt en de bevolking.

6:4. De specialist gebruikt informatietechnologie voor optimale patiëntenzorg en voor bij- en nascholing

Hieronder valt het gebruik maken van patiënt-gerelateerde databases, elektronische informatie en het inzicht hebben in de principes van medische informatica voor het leveren van optimale patiëntenzorg en voor het onderhouden van de eigen deskundigheid.

\section{Professionaliteit}

Omschrijving van het competentiegebied Specialisten hebben een unieke rol in de maatschappij als deskundigen met specifieke kennis, vaardigheden en gedrag die erop gericht zijn de gezondheid en het welzijn van anderen te verbeteren. Specialisten streven de hoogst mogelijke normen na in klinische zorg en ethisch gedrag en streven er tevens naar hun vakkennis continu te perfectioneren. De specialist komt door middel van morele en 
ethische argumenten tot het al dan niet instellen of voortzetten van medische interventies en kan dit verantwoorden. De specialist kan zich voor het goede verstaan van de patiënt inleven in diens vragen, cultuur en levensomstandigheden, maar weet de eigen gevoelens en waarden te onderkennen en deze te scheiden van die van de patiënt. Hij of zij overziet de complexiteit van de begeleiding van patiënten in hun levenseinde en handelt daarin adequaat. Hij of zij reflecteert kritisch op de eigen competentie en professionaliteit.

\section{Algemene competenties Professionaliteit}

\section{7:1. De specialist levert hoogstaande} patiëntenzorg op integere, oprechte en betrokken wijze

Hieronder valt het zich bewust zijn van het centrale belang van de patiënt. Ook valt hier onder het onderkennen van en omgaan met diversiteit in etnische en culturele achtergronden en met maatschappelijke vraagstukken die invloed hebben op het geven van patiëntenzorg en het op peil houden en verdiepen van de relevante kennis, vaardigheden en professioneel gedrag.

\section{7:2. De specialist vertoont adequaat} pesoonlijk en interpersoonlijk professioneel gedrag

Hieronder valt het nemen van de verantwoordelijkheid voor persoonlijke handelingen, het zelfbewust zijn, het behouden van de juiste balans tussen persoonlijke en professionele rollen en het aanpakken van intermenselijke verschillen in professionele relaties.

\section{7:3. De specialist kent de grenzen van de} eigen competentie en handelt daar binnen

Hieronder valt het nemen van een beslissing over of en wanneer andere deskun- digen nodig zijn om bij te dragen aan de zorg voor een patiënt.

7:4. De specialist oefent de geneeskunde uit naar de gebruikelijke ethische normen van het beroep

Hieronder valt inzicht in, en het zich houden aan, de ethische en medische gedragsregels, het herkennen van ethische dilemma's en de behoefte aan hulp om ze indien nodig op te lossen, en het kunnen herkennen van, en reageren op onprofessioneel gedrag elders in de klinische praktijk, daarbij rekening houdend met de lokale en landelijke regelgeving.

\section{Discussie}

Bij de hoge kwaliteit van het initiële medisch onderwijs in Nederland behoort een samenhangend continuüm met de diverse medische vervolgopleidingen. Nadat met het Raamplan 1994 en 2001 het basiscurriculum is voorzien van eindtermen, is het belangrijk dat ook de vervolgopleidingen eindtermen, nu in de vorm van competenties, vastleggen en dat ook duidelijk wordt hoe de inhoud van beide in elkaars verlengde ligt.

Voortschrijdende specialisatie heeft in het verleden geleid tot het schier eindeloos en onduidelijk oprekken van opleidingen met onvoldoende aandacht voor de leerprocessen van arts-assistenten. Omdat de door de assistent in opleiding bereikte competenties nooit een criterium voor de duur van een opleiding hebben gevormd, is een lange opleiding wel altijd veilig maar niet altijd het best. In dat proces van verlenging en steeds verdere specialisatie zijn ook de algemene, voor alle artsen gemeenschappelijke elementen van de geneeskunde, zoek geraakt. Het streven naar een continuüm in de medische opleiding moet daarom op de allereerste plaats betekenen: het hervinden en 
het expliciteren van de gemeenschappelijke opleidingsdoelen in de vorm van competenties. Met de hantering van competenties wordt de outcome van de opleiding belangrijker dan de input (maanden stages, aantallen uitgevoerde verrichtingen). Dit kan een positief effect hebben op de opleidingsduur en mogelijk zelfs op een gedifferentieerde duur. ${ }^{7}$

De algemene competenties moeten daarbij niet alleen (of niet zozeer) beschouwd worden als 'een basis' maar als competenties waarin men gedurende het gehele professionele leven groeit en rijpt. Als zodanig kunnen deze competenties blijvend fungeren als ankers voor de organisatie, inrichting en evaluatie van specialistenopleidingen. Ze creëren duidelijkheid voor opleiders, arts-assistenten en de maatschappij; ze fungeren als richtsnoer voor het handelen van de opleiders zelf en de aan hen toevertrouwde arts-assistenten. Het is van belang om leerprocessen naar onderdelen van deze competenties (zoals kennis, vaardigheden en attitudes) alleen of grotendeels te bevorderen door ze ook afzonderlijk, los van de dagelijkse praktijk, een plaats te geven in cursorisch onderwijs. Professionele medische competentie wordt echter overwegend in de praktijk verworven. Een aanpak waarbij de nadruk te zeer valt op formeel of cursorisch leren, bevordert het verkrijgen van professionele competentie maar zeer ten dele en zou er bovendien toe leiden dat het sterk gevoelde tekort van 'handen aan het bed' nog eens drastisch zou toenemen. Voor sommige specifieke kennis- en vaardigheden is cursorisch onderwijs zeker gewenst, wellicht zelfs noodzakelijk, maar het vinden van de juiste maat is van groot belang. Leren in de klinische praktijk blijft het hart van de opleiding; traditioneel wordt daarop in de opleiding van specialisten ook in hoge mate vertrouwd.
Voor het bereiken en beoordelen van competenties in de praktijk zijn primair de leermomenten die al aanwezig zijn in opleidingsklinieken geschikt of geschikt te maken, zoals de 'visite', het bijgewoonde consult, het ochtendrapport, de bespreking van een 'ontslagbrief', de nabespreking van een 'patiëntdemonstratie' en niet te vergeten het gedrag van de opleider zelf (rolmodel) en de ruimte die hij of zij neemt voor reflectie en feedback op zowel het eigen handelen als dat van de arts-assistent. Het spreekt daarbij voor zich dat om feedback en beoordeling te kunnen geven het noodzakelijk is dat de opleider het handelen van de arts-assistent ook voldoende zelf observeert. Nieuwe instrumenten om groeiende competenties en leerprocessen te zien en te beoordelen bieden daarbij de 'korte klinische beoordelingen' en de 'portfolio'. 8-9

Het leren in de klinische praktijk is een vorm van leren die niet alleen het lerende individu betreft, maar onlosmakelijk is verweven met de sociale context waarin dit leren plaatsvindt. Het goed opleiden van clinici betekent dat naast aandacht voor de arts-assistent ook aandacht voor 'lerende teams', de 'lerende maatschap' en voor de 'lerende ziekenhuisorganisatie' nodig is. Kortom, het vereist een veranderingsbereid en aanpassingsbereid werkklimaat. Dat is een opdracht die in een medische cultuur waarin lange tijd het gezag, de autoriteit, de competitie en de persoonlijke autonomie het heersende paradigma was, niets meer en niets minder dan een cultuuromslag betekent.

\section{Dankbetuiging}

Bij de totstandkoming van de algemene competenties zijn betrokken geweest: $d r$. P. Blok, dr. J.W. Briët, mr. R. Buys, dr. J. Hoorntje, mr. P. van der Lee, dr. J. Molema, dr. C. Plasmans, prof. dr. R. van 
Schilfgaarde, prof. dr. W.J. Schudel, dr. M.F. Schutte, drs. H.M.J. Slot, dr. F. Sprangers en dr. R.J. Stolker.

\section{Literatuur}

1. KNMG. Algemene competenties van de medisch specialist -Bijlage 1 bij het Kaderbesluit CCMS, als bedoeld in artikel B.11, eerste lid, onder e. KNMG; oktober 2003.

2. Merriënboer JJG van, Klink MR van der, Hendriks M. Competenties: van complicaties tot compromis. Een studie in opdracht van de Onderwijsraad. Onderwijstechnologisch Expertise- centrum (OTEC), Open Universiteit Nederland. Den Haag: Onderwijsraad; november 2002.

3. Metz JCM, Verbeek-Weel AMM, Huisjes HJ. Raamplan 2001 Artsopleiding; bijgestelde eindtermen van de artsopleiding. Nijmegen: Mediagroep; 2001.

4. Werkgroep Algemene Eindtermen CCMS. Utrecht; februari 2003.

5. CanMEDS 2000 project. Skills for the new millennium: report of the societal needs working group. Ottawa; september 1996. http//rcpsc.medical.org/ english/publications/canmed_e.html.

6. Miller GE. The assessment of clinical skills/competence/performance. Acad Med 1990;65(9):S63-7.
7. Long DM. Competency-based residency training: the next advance in graduate medical education. Acad Med 2000;75:1178-83.

8. Holdrinet RSG, Bulte J, Bolhuis S. Opleiden van de specialist van straks. Leermogelijkheden in de kliniek beter benutten. Med Contact 2002;57: 1688-90.

9. Cate ThJ ten, Bleker OP, Büller HA, Scherpbier AJJA. Opleiden van medisch specialisten. Achtergronden en praktijk. Houten: Bohn Stafleu Van Loghum; 2003.

\section{De auteurs:}

Prof. dr. O.P. Bleker is voorzitter van het CCMS en hoogleraar Verloskunde-Gynaecologie, Academisch Medisch Centrum te Amsterdam.

Prof. dr. Th.J. ten Cate is wetenschappelijk directeur van het Onderwijsinstituut van het UMC Utrecht en lid van de adviescommissie van het CCMS voor de modernisering van de opleidingen.

Prof. dr. R.S.G. Holdrinet is hoogleraar Ontwikkeling van het Medisch Onderwijs aan het UMC St Radboud te Nijmegen en was in 2002/03 voorzitter van de Werkgroep Algemene Eindtermen van het CCMS.

Correspondentieadres:

Prof. dr. Th.J. ten Cate, Onderwijsinstituut UMC Utrecht, Huispost STR 0.304, Postbus 85060, 3508 AB Utrecht, tel: 030-253 8349,t.j.tencate@med.uu.nl.

\section{Summary}

Since 2001 the Dutch Central College of Medical Specialities of the Royal Dutch Medical Association has been making preparations for the modernisation of all postgraduate specialty training programmes. A first landmark is the definition of general competencies for all specialties to guide the development of educational programmes in the different specialties. This article contains the full text of the document, published in 2003, in which those competencies are described. The competencies are based on the CanMEDS 2000 model with adjustments to adapt them to the specific requirements of the Dutch situation. One of the sources for these adjustments was a report that analysed the Dutch Blueprint of Objectives for Undergraduate Medical Training published in 2001. By 2006 all postgraduate specialty training programmes will have to be targeted at training and assessment of the above-mentioned general competencies and, wherever possible, of additional, discipline-related competencies. (Bleker OP, Ten Cate ThJ, Holdrinet RSG. General competencies of the future medical specialist. Dutch Journal of Medical Education 2004;23(1):4-14.) 